\title{
Syngas Production via Carbon Dioxide Electroreduction Over CdS Nanorods
}

\author{
Jinhua Xiong ${ }^{1, *}$, Xinyu $\mathrm{Bi}^{1}$, Song $\mathrm{He}^{1}$, Changsheng $\mathrm{Cao}^{2, *}$ \\ ${ }^{1}$ Fujian Provincial Key Laboratory of Clean Energy Materials, Longyan University, Longyan \\ 364000, P. R. China \\ ${ }^{2}$ State Key Laboratory of Structural Chemistry, Fujian Institute of Research on the Structural of \\ Matter, Chinese Academy of Science, Fuzhou 350002, China \\ *E-mail: xjh970996937@ sina.com, cscao@fjirsm.ac.cn
}

doi: $10.20964 / 2021.03 .43$

Received: 7 November 2020 / Accepted: 21 December 2020 / Published: 31 January 2021

Herein, CdS nanorods (CdS-NR) was synthesized through a simple and facile solvothermal method. XRD pattern and TEM/HRTEM images indicated that hexagonal CdS nanorods with a diameter of 10 $\mathrm{nm}$ were successfully prepared. When used as electrocatalyst for $\mathrm{CO}_{2}$ reduction reaction $\left(\mathrm{CO}_{2} \mathrm{RR}\right), \mathrm{CdS}-$ $\mathrm{NR}$ afforded an excellent electrocatalytic performance in aqueous electrolyte. In comparison with commercial CdS nanoparticles (CdS-NP), CdS-NR could trigger the electroreduction of $\mathrm{CO}_{2}$ to $\mathrm{CO}$ with a higher faradic efficiency and current densities. The enhanced electrochemical performance of CdS-NR than that of CdS-NP were ascribed to its enhanced adsorption of $\mathrm{CO}_{2}$, charge transfer ability and more exposed active sites. More importantly, it was noticed that $\mathrm{H}_{2}$ generated along with $\mathrm{CO}$, and the generated gas products with controllable ratios exhibited impressive potentials to directly using as syngas.

Keywords: $\mathrm{CdS}$ nanorods, electrocatalysis, $\mathrm{CO}_{2}$ reduction, syngas

\section{FULL TEXT}

(C) 2021 The Authors. Published by ESG (www.electrochemsci.org). This article is an open access article distributed under the terms and conditions of the Creative Commons Attribution license (http://creativecommons.org/licenses/by/4.0/). 